\title{
Building Bridges of Cultural Understanding and Enabling Mutual Learning between East and West
}

\section{What Is in This Special Issue?}

This special issue attempts to build a bridge of cultural understanding between Chinese and Western education and culture. By bridge, we mean the connection that one can make between philosophies and practices of education in the East and West, both past and present. This is a daunting but not impossible task, as shown by the four articles included in this issue. The bridge-building effort can open up an opportunity for dialogues, reflection, learning, and relearning. This is critical in today's world when both East and West are actively seeking new paradigms to reform their educational practices, and looking to each other for inspiration. This bridging process does not come naturally or smoothly. It presents challenges at multiple levels, language, terminology, contexts, or institutional differences. This special issue provides an opportunity to examine these possibilities as well as difficulties.

The four articles included in this issue each showcase how Eastern and Western educational philosophies and practices can be bridged and connected, and can ideally meet in a "third space" for mutual improvement of learning and teaching (Weng \& Lin, 2013). The first article attempts to interlink Confucianism with contemporary Western educational philosophy (Zhao, 2013). Some people argue that there can be no critical thinking or pedagogy in China, or at least there is resistance to critical pedagogy in China (Yu \& Zhao, 2008), but Juanjuan Zhao creatively and persuasively argues that Confucius' teaching and the main ideas in Critical Pedagogy are not dialectically oppositional to each other. Although there are huge differences in era between Confucius, Dewey, Paulo Freire and others, there are commonalities among them. Education has a role for social

\section{Jing LIN ( $₫)$}

College of Education, University of Maryland, College Park, MD 20742, USA

E-mail: jinglin@umd.edu

Jingjing LOU

Department of Education \& Youth Studies, Beloit College, Beloit, WI 53511, USA

E-mail: louj@beloit.edu 
transformation - this is a key underlying theme of the known philosophers of East and West, both past and present. Dialogues, praxis, reflections, and a sense of social equality are essential elements of education for social transformation for these educators.

The second article in this issue connects Taoism ${ }^{1}$ with issues and challenges in Western Education (Keiser, 2013). Taoism is about respecting the invisible, and recognizing "emptiness" as important, which David Keiser interprets as leaving room for meditation, "soft" knowledge, and being self. Yet the current trends of education in the US focus on "solid," tangible core knowledge, which can be normalized or measured. Creativity and intuitive knowing are submerged by the domination of this trend. Taoism can help us to return to another aspect of reality in our life, the invisible, the silent, the tranquil, and the void. David Keiser's paper identifies a very important concern in education, that is the way in which instrumentalism and competitiveness in education are causing our search for the true purpose of life to spiral out of control. He helps open a crack in Western education through Taoism to see teaching, teachers, students, and the learning process differently.

Third are the dialogues and negotiation between Confucian pedagogy and Western pedagogy, and the bridge building of the two (Weng \& Lin, 2013). Xuan Weng and Jing Lin use the metaphor of the Chinese knot to show how the American rope and the Chinese rope interact, intertwine and contradict each other in the knotting process. The process experienced by Chinese teachers teaching in an American context is very interesting. The authors propose a bridging "third space" which provides the opportunity dialogically to connect different cultures and pedagogies. In this space, the Chinese teachers get to know their own culture and teaching better, though often in a frustrating way, but also take up the challenge of adjusting their pedagogy, and adopting a new notion of students as learners and teachers as professionals (instead of students as depositories of knowledge and teachers as ultimate authorities). The process is both intimidating and liberating. Arising from such an experience is a knot that integrates pedagogies from both the Chinese educational tradition and American educational practices, one that needs continuous jiggling, but nevertheless forms refreshing patterns and new possibilities.

The last article by Hongyu Wang (2013) expands our understanding of peace building and peace education from a Confucian and Taoist perspective. Wang's article is an elegant examination of the wisdom of Confucianism and Taoism in peace education. It enriches our understanding of peace education in that, first,

\footnotetext{
1 "Tao" and "Dao" are both used widely and sometimes interchangeably. We do not make them consistent since two forms coexist in current literatures. So are "Taoism" and "Daoism," "Laozi" and "Lao(-) Tzu," and "Dao De Jing" and "Tao Te Ching." — from the editor.
} 
peace is based on inner peace, and yet it is intrinsically connected to outer peace through personal cultivation and social action. Wang argues that in Chinese philosophy, contrary to the Western notion that peace is a state without conflict or violence, direct or indirect (Galtung, 1996), the Taoist concept of building peace and social harmony incorporates differences and diversities. Peace is a dynamic process that works with and works out the conflicts within oneself and among people. Freedom is not to be sacrificed to peace, as one who has achieved internal and external harmony can embrace multiple realities and possibilities.

\section{Challenges in Building a Bridge for East-West Learning, Collaboration, and Integration}

The four articles have demonstrated that it is not only possible but also desirable to build a bridge for East-West learning, integration and collaboration in educational thought and theories. There are also challenges. To facilitate the bridging process, we conclude three major elements that pose difficulties that must be taken into consideration.

The first element that one needs to be cautious about is time and context. Zhao (2013) notices this challenge in her article when comparing Confucius to Dewey, Freire and other critical theorists. Wang (2013) also states how the time and context Laozi, Confucius, and Zhuangzi lived in shaped the way they sought peace within themselves. The philosophers in the articles lived in different times and contexts, so they faced different problems; the ideas they proposed for education responded to the needs and the people of their time. For example, in the era of Confucius, Laozi, and Zhuangzi, people's lives were relatively "simple" due to limited material development. This rendered people able to pursue more intensively moral and spiritual education and advancement more intensively. By contrast, today's schooling is taken over by the predominance of materialism and consumerism and as a result learning has become more mechanical and instrumental. Not to mention that Confucius did not have to deal with the historical memory of colonialism as Freire did. Nor did he face "a flat world" with increasing pressure and acute competition at all levels due to rapid globalization. Hence, while Confucian and Taoist educational philosophies may be very useful and inspiring in guiding today's educational practices, they have to be applied more carefully and reflectively, and with the consideration of more layers and factors.

The second element is interpretation of meaning and terminology in classical texts and language translation. There is great difficulty in bridging language gaps. For example, the meaning of the Tao Te Ching is hard to fathom even for Chinese native speakers. There are multiple versions and interpretations of this classical 
text. When rendered into English, the translated versions can vary even more vastly depending on the understanding of the translators, their personal experience and cultural background. Thus nuances and subtleness have often gotten lost or even twisted in translation. Although the difficulties are considerable, scholarly writing and discussions such as are found in the four articles in this issue have made meaningful attempts to capture the meaning in the classics and illustrate possible ways to make connections between modern educational issues and Eastern philosophies of the past, and between Eastern and Western educational thought and practices.

The third element to pay attention to is systemic institutional differences and challenges. Specifically, different education systems have different realities and challenges. Take standardized examinations as an example. China has a highly centralized educational system, and the US has a highly decentralized one. Hence, teachers' teaching and students' learning are conditioned. As a result, standardized testing functions very differently in each country, and so do any reforms related to it. Understanding systemic institutional differences in both cultures is crucial when one seeks inspiration and attempts to adopt and adapt philosophies and practices from one context to another.

\section{The Possibility and Promise of East-West Educational and Cultural Dialogues}

Having acknowledged difficulties, we see a lot of possibilities and promises in East-West educational and cultural dialogues. The following are some of them.

First and foremost, East-West dialogues offer a valuable opportunity to expand the discussion of possibilities for solving educational problems, especially problems facing both sides. For example, the current educational emphasis is reaching a point that pushes us to only focus on the mechanical, instrumental role of education, and it largely leaves out the moral dimensions and the spiritual needs of teachers and students. This problem is often attributed to the rapid post-war industrialization. Yet, as the scholar of new Confucianism, Liang Shuming pointed out decades ago, it has its deep root in the Western way of "going forward" in human life, weighing heavily on material culture and the conquest of nature, and overly valuing the mind and the intellect over the spirit. This has led to the endless growth of materialism and a rigid mechanicalism, which cause people and society to suffer spiritually (Bary \& Lufrano, 2000). One of the consequences is the weakening of moral and spiritual dimensions of education. This Western way of life and education has expanded to the rest of the world and has become dominant or even the norm due to colonialism in modern history and rapid globalization in more recent times. With more and more 
educators from both the East and the West becoming wary about this disturbing trend, dialogue between the two cultures will open up opportunities first to critically examine and reflect on the constructed reality as Freire did in 1968, and then to call for reevaluation of alternatives such as traditional philosophies from the East, as Liang Shuming proposed almost a century ago.

Both sides have much to learn from each other. While China has been looking to the West to improve its education system and develop its nation since the Self-Strengthening movement in the late 19th century, the two-way dialogue gives China a chance to offer valuable thoughts to the world. For example, as Wang (2013) shows, the dialogue holds promise for advancing some very important roles of education, for example as an enabler of peace, and personal and social transformation. Wang's article enriches our understanding of peace and peace education, that is, peace being a process, a dynamic process of engagement, negotiation, dialogue and the embrace of multiple realities and solutions. She further argues convincingly that harmonizing the outer relationship needs to be based on harmonizing the inner relationship. Inner peace is a process of streamlining one's will with the will of all, of cultivating inner strengths to deal with conflicts, and turning the negative forces in ourselves and society into positive forces.

The dialogue also holds promise for reform in China. Zhao (2013), Keiser (2013), and Weng and Lin (2013) all touch on pedagogy in both Chinese and U.S. contexts. Keiser, and Weng and Lin discuss the possibilities of generating a new environment for learning. Creating a third space, a space for reflection and for self-rejuvenating is critical for creativity in education. Chinese educators have been looking to the West for inspiration on creative and critical education, whereas Zhao and Keiser's articles point to Chinese traditional philosophies for enriched understanding of the role of education, with reference and connection to Western ones.

For both Chinese and American education, the ideas of critical pedagogy and dialogue, as well the cultivation of junzi or exemplary people in Confucianism and Taoism, heighten the connection of educators' sense of morality and personal cultivation towards social transformation. Zhao's article (2013) has not touched too much on this point, but it is extensively discussed by Lin and Wang (2010) who argue that personal moral learning and cultivation is paramount to social transformation. Meanwhile, China's incorporation of Freire's ideas and Dewey's notions of student-centered education would enliven the classroom and help establish new dimensions in the learning process and in the teacher-student relationship. In the current obsession with examinations, this would breathe new air into Chinese education.

The scope of this special issue has some limits. First, the four articles primarily use China as the example for the East and the US as the example for 
the West. We wish there were more articles discussing cases in other Eastern and Western countries so we could show more possibilities and examples. Second, the issue only covers a limited number of educational philosophies. For example, Confucianism and Taoism are the two representative Eastern philosophies discussed here. The two limits of the special issue in part reflect the reality that such bridging exercises are still scarce and that there is indeed a need for both cultures to reach out to each other in dialogue.

\section{References}

Freire, P. (2006). Pedagogy of the oppressed, 30th Anniversary ed. New York, NY: Continuum. Galtung, J. (1996). Peace by peaceful means: Peace and conflict, development and civilzation. International Peace Research Institute, Oslo (PRIO).

Keiser, D. L. (2013). Killing mosquitoes and keeping practice: Teacher education as sustaining paradox. Frontiers of Education in China, 8(1), 28-40. doi: 10.3868/s110-001-013-0004-6

Liang, S. M. (2000). Chinese civilization vis-à-vis Eastern and Western philosophies. In Wm. T. de Bary \& R. Lufrano (Eds., 2nd, vol.2), Sources of Chinese tradition: From 1600 through the twentieth century. New York, NY: Columbia University Press.

Lin, J., \& Wang, Y. J. (2010). Confucius's teaching of virtues and peace education. In J. Lin, J. Miller \& E. J. Brantmeier (Eds). Religion, Spirituality and Peace Education (pp. 3-17). Information Age Publishing.

Wang, H. Y. (2013). Confucian self-cultivation and Daoist personhood: Implications for peace education. Frontiers of Education in China, 8(1), 62-79. doi: 10.3868/s110-001-013-0006-0

Weng, X., \& Lin, J. (2013). Building Bridges in a Third Space: A Phenomenological Study of the Lived Experiences of Teaching Chinese in American Chinese Schools. Frontiers of Education in China, 8(1), 41-61. doi: 10.3868/s110-001-013-0005-3

Yu, H. S., \& Zhao, C. H. (2008). The Practices of Critical Pedagogy and the Preliminary Analysis of Its Application in Chinese Education. International Education Studies. 1(3), $112-117$.

Zhao, J. J. (2013). Confucian self-cultivation and Daoist personhood: Implications for peace education. Frontiers of Education in China, 8(1), 9-27. doi: 10.3868/s110-001-013-0003-9 